\title{
Mujeres campesinas de Inzá - Tierradentro, Cauca: una mirada desde los feminismos decoloniales
}

Mulheres camponesas de Inzá - Tierradentro, Cauca: um olhar dos feminismos decoloniais

Peasant women from Inzá-Tierradentro, Cauca: a view from decolonial feminisms

Jazmin Yulieth Cuellar Diaz*

Juano Zuluaga Garcia**

\begin{abstract}
Resumen - Los feminismos decoloniales son el resultado de un desarrollo social, político, histórico y epistemológico de movimientos feministas críticos, como el feminismo negro afroamericano. Lo decolonial implica situar los efectos de la colonialidad y forjar escenarios emancipatorios, dentro de los cuales, el feminismo popular también constituye una herramienta importante para consolidar alternativas epistémicas que reconozcan y potencien las subjetividades y procesos socio-organizativos de lo subalterno. Motivo por el cual, este artículo tiene como objetivo interpretar y visibilizar el proceso del Comité de Mujeres de la Asociación Campesinas de Inzá Tierradentro (CaucaColombia) desde la perspectiva de los feminismos decoloniales, teniendo presente que sus dinámicas de resistencia, territorialización, defensa del territorio, reconstrucción del tejido social y fortalecimiento del modelo comunitario, autónomo y popular, constituyen un aporte significativo para la construcción de alternativas a los discursos hegemónicos de la colonialidad del poder, el saber y el ser. Palabras claves: colonialidad; feminismo decolonial; feminismo popular; Comité de Mujeres.
\end{abstract}

Resumo - Os feminismos decoloniais são o resultado do desenvolvimento social, político, histórico e epistemológico de movimentos feministas críticos, como o feminismo negro afro-americano. O decolonial implica situar os efeitos de colonialidade e forjar cenários emancipatórios, dentro dos quais o feminismo popular também é uma ferramenta importante para consolidar alternativas epistêmicas que reconheçam e aprimorem as subjetividades e processos sócio-organizacionais do subalterno. Motivo pelo qual este artigo tem como

\footnotetext{
* Politóloga de la Universidad Surcolombiana-Colombia e investigadora del Centro de Investigación e Inter-Acción Social del Sur Colombiano. E-mail:yuliethcuellard@gmail.com. ORCID: https://orcid.org/0000-0003-3562-1088.

** Estudiante de último semestre del pregrado de Ciencia Política de la Universidad Surcolombiana e investigador del Centro de Investigación e Inter-Acción Social del Sur Colombiano. E-mail: juano.zuluaga@hotmail.com. ORCID: https:/ /orcid.org/0000-0002-5179-2875.
} 


\begin{abstract}
objetivo interpretar e tornar visível o processo do Comitê de Mulheres da Asociación Campesina de Inzá Tierradentro (Cauca - Colômbia), do ponto de vista dos feminismos decoloniais, tendo em vista que suas dinâmicas de resistência, territorialização, defesa do território, reconstrução do tecido social e fortalecimento do modelo de comunidade autônoma e popular constituem uma contribuição significativa para a construção de alternativas aos discursos hegemônicos da colonialidade do poder, conhecimento e ser.
\end{abstract}

Palavras-chave: colonialidade; feminismo decolonial; feminismo popular; Comitê de Mulheres.

\begin{abstract}
Decolonial feminisms are the result of a social, political, historical, and epistemological development of critical feminist movements, such as black African-American feminism. The decolonial implies situating the effects of coloniality and forging emancipatory scenarios, within which popular feminism also constitutes an important tool to consolidate epistemic alternatives that recognize and enhance the subjectivities and socio-organizational processes of subalternity. Therefore, this article aims to interpret and make visible the process of the Women's Committee of the Peasant Association of Inzá Tierradentro (Cauca, Colombia) from the perspective of decolonial feminisms, bearing in mind that their dynamics of resistance, territorialization, defense of the territory, reconstruction of the social fabric, and strengthening of the community, autonomous, and popular model constitute a significant contribution to the construction of alternatives to the hegemonic discourses of the coloniality of power, knowledge, and being.
\end{abstract}

Keywords: coloniality; decolonial feminism; popular feminism; women's committee.

\title{
Introducción
}

Uno de los factores determinantes en la consolidación del sistema capitalista, el cual es de carácter homogeneizante, globalizado, heteropatriarcal y colonial, es la invasión de "América" el 12 de octubre de 1492. Esta invasión y la imposición de las colonias, basadas en una división centro (Europa) y periferia (América), le permitió al sistema predominante desarrollar sus fuerzas productivas, obtener materias primas, saquear el oro y demás riquezas del continente y expandir su proyecto de dominación a escala global a partir de un proceso de despojo, aniquilamiento de pueblos indígenas y violencia epistémica. Pese a la pretensión de universalizar la historia oficial del continente americano, que niega los procesos sociales, políticos y organizativos de las comunidades que habitaron este continente antes de la llegada de los europeos, los pueblos originarios han creado procesos de resistencia al eurocentrismo y al proyecto de occidente que van desde la disputa de las prácticas discursivas y la recuperación de sus lenguas nativas hasta el reconocimiento del continente como Abya Ayala ${ }^{1}$; siendo este un término propio que han venido tejiendo los pueblos

\footnotetext{
${ }^{1}$ Abya Yala quiere decir en la lengua del pueblo kuna "tierra madura", "tierra viva" o "tierra que florece", se usa para hacer referencia a América.
} 
originarios en contraposición a la expresión "América" impuesta por occidente, la cual se constituye como una apuesta contrahegemónica que reivindica la construcción y reconstrucción social e histórica del sentido político e identitario de las comunidades y los territorios, en donde las prácticas discursivas son pieza fundamental de la decolonización del pensamiento (PORTO-GONÇALVES, 2016).

Las dinámicas y formas de dominación y opresión expuestas anteriormente, son concebidas por las corrientes feministas latinoamericanas a partir de la relación intrínseca entre capitalismo, colonialidad y heteropatriarcado, que tiene repercusiones directas y diferenciadas sobre los cuerpos de las mujeres y beneficia los mercados económicos y capitalistas con la explotación de su trabajo (SUÁREZ, 2017, p. 7). Lo anterior conlleva a dinámicas de resistencia y construcción de otros mundos posibles por parte de los movimientos feministas a lo largo de la historia de la humanidad.

De esta manera, desde el reconocimiento de diferentes cosmovisiones y realidades, resulta pertinente hablar de feminismos en tanto existe una variedad de corrientes y perspectivas que lo diversifican. Así pues, los movimientos feministas han tenido un desarrollo histórico a saber: tras la abolición de la esclavitud en Estados Unidos, se creó el movimiento sufragista a finales del siglo XIX, dentro del cual se generó una división entre las mujeres blancas y negras a raíz de que las primeras no reconocían como sujeto político a las segundas, es decir, a través del racismo y el sexismo se generaron lógicas de exclusión, que pusieron en evidencia la existencia de patrones de colonialidad con perspectivas hegemonizantes y pretensiones universalistas dentro de los mismos movimientos feministas. Como respuesta, surge el feminismo negro afroamericano, que logró vislumbrar las diferentes formas de opresión de la mujer, creando así la matriz de dominación plasmada en la teoría de la interseccionalidad, que considera género, etnia, raza, clase y orientación sexual en sus prácticas y reflexiones.

Los aportes epistémicos del feminismo negro y su apuesta por decolonizar el feminismo blanco, eurocéntrico, hegemónico y racista, sirvió de base para otros feminismo críticos, como los feminismos decoloniales, los cuales, según Yuderkys Espinosa Miñoso (2012, p. 151) son herederos del feminismo negro. Los feminismos decoloniales, tal como se argumentará en el artículo, son una apuesta epistémica y teórica importante para hacerle frente al eurocentrismo y a la colonialidad del ser, el saber y el poder, así como también para generar articulación desde sectores y campos subalternos para construir alternativas de emancipación. Cabe mencionar que dentro de los feminismos decoloniales convergen diferentes corrientes y formas de expresión, siendo el feminismo popular una de ellas.

Si bien el feminismo popular es una categoría de análisis, que se enmarca dentro de los feminismos decoloniales, este no es una perspectiva abstracta. Contrario a esto, su esencia recae en expresiones concretas desde abajo, desde dinámicas subalternas que de una manera u otra aportan a 
subvertir las lógicas de poder. De esta manera, el feminismo popular no existe de manera per se, sino que dialoga, retoma y se retroalimenta de los sentires, saberes y pensares autónomos, comunitarios, campesinos, indígenas, afros y populares urbanos, que tienen lugar en las organizaciones y procesos territoriales de resistencias y luchas contra las distintas formas de dominación y en pro de la construcción de proyectos epistémicos de carácter emancipatorios. Un claro ejemplo de lo anterior es la experiencia del Comité de Mujeres de la Asociación Campesinas de Inzá Tierradentro (en adelante, ACIT), en la medida que sus dinámicas de territorialización y sus prácticas cotidianas están ligadas a la soberanía alimentaria, la defensa del territorio y el fortalecimiento de un modelo comunitario, autónomo y popular con la capacidad política y organizativa de consolidar alternativas que le hagan frente a los discursos hegemónicos de modernidad, desarrollo y colonialidad.

Por tales motivos, el presente artículo tiene como objetivo interpretar y visibilizar la experiencia y el proceso del Comité de Mujeres de la ACIT desde la perspectiva de los feminismos decoloniales, reconociendo su articulación con los postulados del feminismo popular en tanto conciben el trabajo de base, de carácter colectivo, autónomo y comunitario como elementos primordiales para los procesos de transformación social.

\section{El giro decolonial como alternativa epistémica y política a la colonialidad}

El giro decolonial como apuesta epistémica y política asevera que las bases de la estructura de las colonias de América del Sur no se modificaron tras el proceso de independencia, sino que se desató una transición del colonialismo a la colonialidad global, el cual -enmarcado en el capitalismo globalizado-, profundiza las exclusiones derivadas de las jerarquías epistémicas, estructurales, raciales/étnicas y de género/sexualidad promovidas por la modernidad (CASTRO-GÓMEZ; GROSFOGUEL, 2007; MIGNOLO apud CONTRERAS; TRUJILLO, 2017).

Aníbal Quijano (2000, p. 2009) citado por Contreras y Trujillo (2017, p. 151) tiene unos planteamientos que permiten vislumbrar los efectos de la colonialidad y trazar horizontes teóricos entorno al giro decolonial. A través de bases teóricas sólidas, desentraña las ramificaciones del colonialismo sobre el Abya Ayala, poniendo en evidencia que en este convergieron dos procesos históricos, que a su vez, se consolidaron como elementos relevantes del nuevo patrón de poder: por un lado, las lógicas de superioridad/inferioridad creada en las relaciones entre conquistadores y conquistados con base en la naturaleza biológica; y por otro, la forma en que se articuló el control del trabajo con sus productos en términos de capital. 
Este marco de cosas perfiló a Europa como el centro capitalista y a sus colonias como las periferias; conllevando a que Europa centrara en su hegemonía el dominio de toda expresión de control sobre la subjetividad y la cultura, haciendo énfasis en el conocimiento y su construcción (QUIJANO, 2000 apud CONTRERAS; TRUJILLO, 2017, p. 151). Lo anterior, desarrolló y consolidó el eurocentrismo y etnocentrismo acudiendo a la homogeneización del conocimiento a través de la supremacía epistémica que logró perpetuar una geopolítica del conocimiento (CONTRERAS; TRUJILLO, 2017, p. 151).

Un aspecto fundamental para abordar, analizar, criticar y proponer alternativas a la colonialidad, es evidenciar cómo se ha configurado el "paradigma del otro", como un "pensamiento crítico y utopístico que se articula en todos aquellos lugares en los cuales la expansión imperial/colonial negó la posibilidad de razón, pensamiento y de pensar el futuro" (MIGNOLO, 2003 apud CONTRERAS; TRUJILLO, 2017, p. 150). Desde esta premisa, la otredad, de acuerdo con Contreras y Trujillo (2017, p. 150) tiene lugar como un espacio negado, dada la manera en que el conocimiento se ha ido construyendo desde una perspectiva universal, anulando así las múltiples experiencias e historias locales y su potencial en las diferentes maneras de construir conocimiento; esto, en términos de Zulma Palermo (2010), citado por Contreras y Trujillo (2017, p. 150), "se traduce en una violencia epistémica que de manera silenciosa se impone como pensamiento único".

\section{Construcción de feminismos decoloniales como proyecto contrahegemónico de emancipación}

La apropiación del modelo de pensamiento occidental, patriarcal y colonial sobre el pensamiento, cultura, territorios y procesos de los pueblos del Abya Ayala, limitó y determinó las agendas de los movimientos de mujeres - feministas y no feministas -, a la lucha de derechos enmarcados en las dinámicas del sistema que reproduce unas lógicas, roles, discursos y una cultura sobre los cuales se estructura la sociedad patriarcal. De tal forma, la lucha de las mujeres que se hizo visible desde finales del siglo XIX hasta finales del siglo XX en América Latina no fue más que la lucha de mujeres heterosexuales, blancas y burguesas por ser reconocidas como sujetas autónomas dentro de un sistema económico, político y social que explotaba, subyugaba, y violentaba los derechos de sus semejantes indígenas, campesinas, negras y pobres históricamente invisibilizadas.

No fue sino hasta finales del siglo XX que los feminismos inician a forjar una teoría política feminista enmarcada en el reconocimiento y cuestionamiento de las distintas formas de opresión por parte del sistema económico, político y social. La ampliación política de los movimientos 


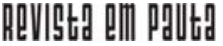

\} MUJERES CAMPESINAS - DIAZ, J. Y. C.; GARCIA, J. Z. \}

DOI: $10.12957 /$ rep.2021.56084

feministas en la región, ligada a la construcción de nuevas epistemologías enmarcadas en el giro decolonial, permitió repensar las categorías de género y mujer en transversalidad a la raza, clase y sexualidad, entre otros. Esta perspectiva insterseccional, nacida de los feminismos negros estadounidenses, reconoce la multiplicidad de cosmovisiones, saberes, luchas, y propuestas emancipatorias como respuesta a ese feminismo blanco, occidental y hegemónico que a lo largo de la historia ha pretendido universalizar la experiencia de todas las mujeres sin concebir el impacto que tiene el contexto social, cultural, y económico en las relaciones de poder entre hombres y mujeres (MARCIALES, 2011, p. 129). Los feminismos decoloniales deconstruyen la categoría universal de mujer, debido a la existencia de jerarquías entre las mismas mujeres por medio de la raza, etnia, clase, sexualidad o nivel de formación (CONTRERAS; TRUJILLO, 2017, p. 153).

Así pues, los feminismos decoloniales se enriquecen, retroalimentan y dialogan con diversas tradiciones críticas frente a la modernidad occidental y heteropatriarcal; y a su vez, se constituyen como una interpelación a la propia teoría feminista de corte eurocéntrica. Un ejemplo de lo anterior es la coloniadalidad que también ha permeado a ciertos movimientos feministas, que reproducen lógicas sexistas, racistas, homófobas y liberales. Precisamente, una fortaleza importante de los feminismos decoIoniales es que plantean una crítica hacia dentro, es decir, no solo develan las formas de colonización del poder, el ser y el saber, sino también los mismos discursos hegemónicos que han estructurado ciertos feminismos occidentales, eurocéntricos y coloniales.

En este sentido, se hace preciso recalcar que los feminismos decoloniales reconocen el aporte de las académicas blancas, siempre y cuando estén comprometidas con proyectos subalternos, tanto en el Abya Ayala como en el globo (ESPINOSA, 2012, p. 150). Lo anterior resulta interesante en la medida en que el debate trasciende del color de piel; lo que implica poner en tela de juicio, no su condición de mujer blanca, sino el lugar de enunciación que responde, en algunos casos, a marcos académicos y políticos de dominación política y epistémica.

Este feminismo decolonial, surgido de los pueblos que habitan del Abya Ayala, es el heredero del legado del feminismo negro, de color y tercermundista gestado en Estados Unidos a mediados del siglo XIX, como respuesta a las lógicas racistas y excluyentes de los feminismos blancos, hegemónicos y europeizados (ESPINOSA, 2012). En este sentido, el feminismo negro está cargado de una perspectiva contrahegemónica encaminada a romper con la idea de superioridad/inferioridad del feminismo blanco hegemónico, partiendo del reconocimiento identitario de elementos que son transversales a la condición de ser mujer negra, tales como la raza, el género, la sexualidad y la clase, entre otras. De allí que el feminismo negro construyera la interseccionalidad como una apuesta política y teórica. 


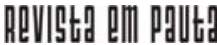

\} MUJERES CAMPESINAS - DIAZ, J. Y. C.; GARCIA, J. Z. \}

DOI: $10.12957 /$ rep.2021.56084

Se hace preciso resaltar aquí que el carácter emancipatorio del feminismo negro reside en el contexto histórico-social en el que este se materializó. La abolición de la esclavitud trajo consigo un nuevo proceso de transición social en el que la discriminación racial se convirtió en el "moderno" criterio de desigualdad (JABARDO, 2012, p. 29). Con relación a lo anterior, esa afectación diferenciada, producto de las relaciones de poder que recaen sobre los cuerpos y el hecho de ser mujer negra, fueron elementos constitutivos de las luchas del movimiento feminista negro por ser reconocidas como sujetas políticas activas dentro de las demandas sociales y políticas.

Teniendo como precedente este proceso de mujeres negras en EE.UU., la búsqueda y creación de una identidad propia por parte de los movimientos feministas decoloniales estuvo atravesada por el reconocimiento de su historia: una historia protagonizada por el genocidio indígena, la violencia epistémica, la esclavitud, la negación cultural y la invisibilización del conocimiento. Asimismo, en el camino de consolidación de su identidad, los feminismos decoloniales, al tener un criterio subalterno, han tenido que resistir a los feminismos europeos y norteamericanos, y a su vez al pensamiento político latinoamericano que ha desconocido, o reconoce escasamente, el papel de las mujeres a lo largo de la historia (WIGDOR; ARTAZO, 2017).

Ahora bien, en el marco de la búsqueda de esta identidad por parte de los feminismos decoloniales desarrollados en la región han surgido nuevas expresiones de organización y nuevas propuestas epistemológicas que dan cuenta de las realidades que atraviesan las mujeres del Abya Ayala; entre estas, se encuentra el feminismo popular que sienta sus bases en las necesidad de generar resistencias y alternativas emancipatorias que hagan frente a las distintas formas de dominación que afectan e intervienen sobre los cuerpos, territorios y comunidades, y a su vez, sean capaces de remover los cimientos del sistema capitalista-patriarcal a partir de la creación de subjetividades subalternas que re-piensen y de-construyan las lógicas y realidades en las que se desarrolla el ser mujer (KOROL, 2016). El feminismo popular trasciende de la lucha en contra del patriarcado y sus opresiones, va más allá de la identificación de clase como única condición de dominación y reconoce la heterogeneidad de cosmovisiones, saberes y lugares de enunciación que emanan desde los distintos grupos de mujeres organizadas y no organizadas.

Su esencia reside así, en asumir las condiciones que crean lo popular - como el ser campesina, indígena, obrera o ama de casa - desde un carácter "emancipatorio, de posibilidad, de movilización, no como condicionante o como un determinismo social que imposibilita a los sujetos la transformación de su subjetividad y de su realidad material" (VELOZA apud SUÁREZ, 2017, p. 51-52). En el feminismo popular, gestado desde las bases sociales y sus prácticas autónomas, prima, ante todo, el accionar político y 


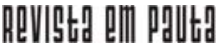

\} MUJERES CAMPESINAS - DIAZ, J. Y. C.; GARCIA, J. Z. \}

DOI: $10.12957 /$ rep.2021.56084

la creación de identidades individuales y colectivas como respuesta a las dinámicas de opresión diferenciada que recae sobre los cuerpos feminizados. Concebir el cuerpo como un territorio en disputa se convierte en un elemento fundamental de reivindicación y apropiación territorial de luchas encaminadas al reconocimiento como sujetas políticas.

En suma, los feminismos decoloniales, sus precedentes y las corrientes que de este han surgido (como el feminismo popular), son una herramienta teórico-práctica no solo para develar los impactos de la modernidad, la colonialidad y el eurocentrismo, sino también para crear y fortalecer proyectos alternativos de emancipación. Así, los feminismos decoloniales son claves para deconstruir los feminismos europeizados, hegemónicos, con pretensiones universalizantes de categorías como "mujer", que son excluyentes y reproducen las lógicas coloniales y occidentales. Asimismo, son una apuesta interesante para la deconstrucción de discursos hegemónicos que potencian procesos subalternos de transformación social, generando diálogo con otros saberes, distintas subjetividades y otras formas de construcción de conocimiento situados en el Abya Yala; por tanto, son una apuesta epistémica contrahegemónica para descolonizar el poder, el ser y saber y edificar categorías, metodologías y métodos con los cuales se pueda interpretar y transformar la realidad social.

\section{Aproximación al Comité de Mujeres de la Asociación Campesina de Inzá Tierradentro - Cauca}

El Comité de Mujeres de la Asociación Campesina de Inzá Tierradentro, o también conocida como Asociación de Mujeres por Inzá, es una organización gestada en el año 2001 en el marco de la conmemoración del 8 de Marzo en el municipio de Inzá, departamento del Cauca, una región ubicada al Sur de Colombia caracterizada por ser históricamente un territorio donde coexisten luchas, disputas y resistencias. El Cauca ha sido y es uno de los territorios con mayor nivel de conflictividad armada ocasionada por grupos legales e ilegales en el país. La lucha por el control del territorio y la defensa de intereses estratégicos por parte de grupos paramilitares y guerrillas, como el Ejército de Liberación Nacional (ELN) y las Fuerzas Armadas Revolucionarias de Colombia (FARC), junto a las acciones del Ejército Nacional, han afectado fuertemente a las poblaciones campesinas, indígenas y afros que habitan este histórico territorio.

Las dinámicas de conflictividad, que todavía persisten, la ausencia de entidades que garanticen las mínimas condiciones de vida y la poca conectividad y accesibilidad del departamento con el resto del país, ha determinado en cierta parte el sistema social y económico de esta región, el cual ha estado ligado a la producción de coca, marihuana y amapola, 
como uno de los principales sustentos económicos de las comunidades para mejorar su calidad de vida (DUARTE, 2013, p. 29).

Continuando con la caracterización del territorio en mención, el departamento es un referente nacional de luchas y resistencias por parte de comunidades indígenas y campesinas, quienes han desarrollado y consolidado procesos de organización social para hacerle frente a las dinámicas y flagelos del conflicto armado, político y social interno. Actualmente, existe el Consejo Regional Indígena del Cauca (CRIC) como órgano de mayor representación indígena en el departamento, y diversas organizaciones campesinas, entre estas la Asociación Campesina de InzáTierradentro (ACIT) que confluyen a nivel departamental y nacional para adelantar sus agendas conjuntas.

La creación de la ACIT se remonta al año de 1997, teniendo como principal bandera de lucha el reconocimiento de los campesinos como sujetos de derechos y la defensa del territorio. En el esfuerzo por consolidar su ejercicio organizativo, político y social a nivel municipal, se crearon 6 comités, entre estos el Comité de Mujeres, que nace como una iniciativa de mujeres campesinas para hacerle frente a las dinámicas del conflicto armado, social y político que las ha afectado de forma diferenciada, directa o indirectamente, con acciones como la violencia sexual, reclutamiento forzado, homicidios o señalamiento; en otras palabras, este proceso fue creado con el fin de

visibilizar y reconocer las consecuencias diferenciadas de la implementación de políticas neoliberales y su coexistencia con el sistema patriarcal sobre sus vidas y cuerpos, y específicamente el contexto de conflicto armado interno y la violencia que prevalecen en el país. (ASOCIACIÓN DE MUJERES POR INZÁ, 2019, p. 65-69).

En esta medida, la creación del Comité de Mujeres dentro de la ACIT surge como una apuesta por parte de mujeres campesinas para llevar a cabo la reivindicación de sus derechos, la defensa del territorio y la construcción de un buen vivir en las comunidades campesinas. Desde su creación han forjado y consolidado el comité entorno a los valores de solidaridad, colectividad, compañerismo y ayuda mutua. Sus apuestas políticas aportan al fortalecimiento de los feminismos decoloniales, dentro de los cuales converge el feminismo popular, teniendo en cuenta que enfocan su trabajo en un modelo comunitario y autónomo, fundamentado en el enfoque de género, ecología social y popular y construcción de paz.

Las apuestas desarrolladas en su trayectoria organizativa, enfocadas en la soberanía alimentaria como principal eje de trabajo, les ha permitido obtener un reconocimiento a nivel local, regional y nacional en términos de su capacidad organizativa. Además, han logrado ampliar su agenda a temas de formación, autonomía económica y empoderamiento político. Es preciso resaltar que, aunque son parte de la ACIT como comité, 


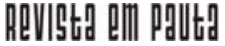

\} MUJERES CAMPESINAS - DIAZ, J. Y. C.; GARCIA, J. Z. \}

DOI: $10.12957 /$ rep.2021.56084

estas poseen una personería jurídica como Asociación de Mujeres por Inzá, lo cual les brinda autonomía para la ejecución de recursos y proyectos. Es mediante esta figura que han logrado tejer redes de apoyo y solidaridad con organizaciones e iniciativas de mujeres como Ruta Pacífica, Red de Educación Popular para Mujeres de América Latina (REPEM), Espacio Femenino Internacional (EFI) o la Universidad del Cauca (CAMPRUBí, s. f.).

\section{Soberanía alimentaria y territorio}

"el territorio es nuestro cuerpo, es el lugar donde habitamos, con el que nos identificamos, es donde están nuestros recuerdos y donde proyectamos nuestros sueños...El que nos despierta emociones y sentimientos. Donde construimos relaciones con la naturaleza, con la comunidad y con nosotras mismas. Porque el territorio es memoria y la memoria somos nosotras" ${ }^{2}$. (Comité de Mujeres de la Asociación Campesina de Inzá Tierradentro, 2019).

El mandato social que ha relegado históricamente el papel de la mujer a la esfera privada y que ha impuesto una serie de roles y valores sobre estas, ha sido fundamental para la creación e implementación del orden político y social sobre el cual se ha estructurado la sociedad colombiana, la cual violenta, segrega e invisibiliza a la mujer como sujeta política autónoma, deliberante, militante y forjadora de alternativas de emancipación. El sistema patriarcal se hace presente en todos los escenarios de la vida cotidiana de las mujeres, y, por tanto, los derechos ganados en las últimas décadas no son suficientes frente a la violencia social y cultural que las afecta. Como respuesta a todas estas formas de dominación ejercidas por el sistema capitalista patriarcal, heteronormativo, moderno y colonial sobre los territorios, cuerpos y comunidades, se han creado procesos y propuestas de emancipación y resistencia por parte de distintas organizaciones y movimientos de mujeres. xEstos procesos y propuestas se han centrado en la consolidación y formación de una base social sólida, capaz de generar conmociones en el sistema a partir de la creación de subjetividades, individuales y colectivas, encaminadas a transformar y construir realidades que respondan de una forma integral a las necesidades de los pueblos (KOROL, 2016).

En consecuencia de lo anterior, las mujeres del Comité han decidido llevar a cabo proyectos de soberanía alimentaria como una alternativa de defensa del territorio y de sustento económico en su intento de contrarrestar las lógicas del sistema de mercado global que predomina en la sociedad contemporánea e impone prácticas de consumo a los territorios.

${ }^{2}$ Concepto de territorio construido en un escenario asambleario del Comité de Mujeres. Este fue expuesto en el "Encuentro de Pensamiento Crítico y Construcción de Paz en la Región Surcolombiana. Tejiendo diálogos desde el sur" por la representante de la Asociación Stefany Robles. 


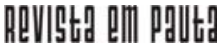

\} MUJERES CAMPESINAS - DIAZ, J. Y. C.; GARCIA, J. Z. \}

DOI: $10.12957 /$ rep.2021.56084

En este mismo sentido, han optado por priorizar el trabajo colectivo y desarrollar dinámicas de intercambio o bien conocido "trueque" como prácticas propias del buen vivir y formas de habitar el Abya Ayala desde lógicas de cooperación, solidaridad y ayuda mutua, rompiendo así con el individualismo y la acumulación de riquezas características propios del liberalismo y el capitalismo.

Esta apuesta es el resultado de un proceso de reconocimiento del entorno, la historia, el contexto, y la realidad del territorio que en su momento las rodeaba. El déficit de alimentos, la falta de espacios donde confluir y la dependencia económica fueron las principales motivaciones para materializar esta propuesta, la cual inició con la construcción de huertas comunitarias para el consumo familiar y el mercado local; siguió con la preservación de semillas al reconocer el significado material y simbólico de esta en la esencia del ser campesino; $y$, posteriormente, ha venido trascendiendo a la necesidad generar espacios de formación y capacitación de las mujeres del Comité en temas relacionados con las formas de producción posibles, recursos naturales o identidad campesina, todo esto sin desconocer las prácticas, saberes y costumbres locales (MORALES, 2011, p. 337).

Ahora bien, entendiendo las realidades que atraviesan el ser campesina y campesino, se concibe aquí la soberanía alimentaria como un proceso que permite la construcción de movimientos sociales, la creación de nuevos relacionamientos sociales y el empoderamiento político, social y económico de las comunidades en tanto hacen frente a la visión neoliberal que mercantiliza todos los aspectos de la vida cotidiana; así, la soberanía alimentaria no solo es una alternativa de sustento para estas mujeres, sino que se ha convertido en una respuesta política y económica a las cadenas de producción y mercado de un sistema que prioriza el capital y la acumulación de riquezas sobre el bienestar humano, el buen vivir y la sostenibilidad ambiental (COORDINACIÓN EUROPEA VÍA CAMPESINA, 2018, p. 7).

Reconstruir las relaciones existentes entre el ser humano y la naturaleza, caracterizadas actualmente por la sobreexplotación de los primeros sobre lo segundo, supone ser uno de los ejes centrales de la soberanía alimentaria, y así mismo del Comité de Mujeres de Inzá - Cauca, quienes han logrado resignificar las relaciones sociales de la comunidad con su entorno, al desarrollar un proceso basado en la solidaridad y el buen vivir, respetando, reconociendo y reivindicando el territorio de la siguiente manera: por un lado, han logrado forjar redes afectivas basadas en la amistad, el respeto, la cooperación y la ayuda mutua entre ellas, y la reconstrucción del tejido social, lo cual se ve reflejado en el proceso de acompañamiento a la hora de sembrar y cuidar los productos en tanto reconocen y entienden los tiempos, capacidades y conocimientos de sus compañeras; y por otro lado, transforman la relación que estas poseen con el territorio, considerando que este 
No es solamente una porción de tierra delimitada con su complejidad biofísica (relieve, condiciones ambientales, biodiversidad [...] es sobre todo, un espacio construido socialmente, es decir, histórica, económica, social, cultural y políticamente. (SOSA, 2012, p. 7).

La apropiación del territorio mediante la soberanía alimentaria y la reivindicación de la identidad campesina, reflejada en el cuidado de las semillas nativas por parte las mujeres del Comité, han permitido y brindado condiciones para la creación de escenarios y espacios de formación y participación con enfoque de género encaminados a la reconfiguración de roles, que le ha permitido a estas superar las barreras impuestas por el sistema patriarcal. Este marco de cosas ha posibilitado la plena participación de las mujeres del Comité de la ACIT en la esfera de lo público, debido a que han promovido y convergido en dinámicas de transformación socio-territorial y participación política de su municipio y de la sociedad en general. Todo esto supone un empoderamiento político y organizativo de las mujeres del Comité llevando a cabo propuestas y proyectos que, de una u otra forma, aportan a la decolonialidad del poder, el ser y el saber y a la construcción de horizontes utópicos emancipatorios, emanado de bases populares, comunitarias y autónomas.

\section{Conclusiones}

El etnocentrismo, como resultado del proyecto de modernidad y colonialidad desarrollado por occidente, ha obtenido respuestas por parte de movimientos sociales y académicos y académicas del Abya Ayala, quienes desde perspectivas críticas han aportado a la decolonización del poder, el ser y el saber a partir de la creación de teorías alternativas a la visión de modernidad, progreso y desarrollo. Entre estos podríamos nombrar a María Lugones, Rita Segato, Silvia Cusicanqui, Yuderkys Espinoza, Arturo Escobar, Aníbal Quijano, entre otros.

Este giro decolonial, junto al legado del feminismo negro estadounidense, han brindado las herramientas teóricas y prácticas para sentar las bases de los feminismos decoloniales, siendo estos un vehículo que permite construir horizontes utópicos alternativos a la modernidad y a la colonialidad. Es así como resulta imperante reconocer y articular diferentes campos de luchas como respuesta a los discursos de racismo, desarrollo, progreso y civilización que históricamente han invisibilizado reivindicaciones locales en el Abya Ayala.

Con base en lo anterior, el proceso adelantado por el Comité de Mujeres de la Asociación Campesinas de Inzá Tierradentro (Cauca -Colombia), constituye una experiencia interesante, ya que si bien desde el plano teórico estas no se reconocen como feministas, resulta pertinente abordarlas desde los feminismos decoloniales, debido a que: por un lado, 
este constituye una respuesta a la invisibilización por parte de este sistema capitalista, patriarcal, eurocéntrico y colonial hacia las identidades individuales y colectivas que históricamente han forjado mujeres campesinas, indígenas y afros que habitan el territorio; y que por otro lado, las teorías decoloniales trascienden de la descolonización, proponiendo alternativas "otras" con miras a subvertir el poder hegemónico, lo que posibilita poner en evidencia los efectos desatados por la colonización y la colonialidad del poder, el saber y el ser, deconstruyendo así estas subjetividades y generando condiciones epistémicas de emancipación (GÓMEZ et al., 2017, p. 51-52).

En esta medida, el proceso de las mujeres campesinas en Inzá (soberanía alimentaria, defensa del territorio, reconstrucción del tejido social y fortalecimiento del modelo comunitario, autónomo y popular) es, además de una propuesta de resistencia a las dinámicas de globalización y colonialidad, un proyecto emancipatorio que rompe, de una manera u otra, con la imposición del mercado trasnacional y globalizante, que desterritorializa a los campesinos de sus actividades productivas, los despoja de sus identidades y desconoce y elimina las formas alternativas de producción y comercialización enmarcadas en lógicas populares y comunitarias.

Estos procesos permiten recuperar las identidades y prácticas socioproductivas de campesinas, las cuales han intentado extinguir los discursos dominantes de la modernidad, el progreso, la globalización y la civilización. Asimismo, promueven iniciativas encaminadas a la creación de relaciones amenas entre las comunidades y el medio ambiente, lo cual subvierte la premisa del capitalismo salvaje que concibe que los recursos naturales del entorno deben estar al servicio de la humanidad con fines acumulativos.

Así pues, se puede establecer que la experiencia de organización y confluencia de las mujeres de Inzá - Cauca en un escenario como el Comité, ha aportado indiscutiblemente al proceso de despatriarcalización y transformación de sus condiciones de vida como mujer (pobre, campesina, habitante de un territorio considerado periférico y con alto impacto del conflicto armado interno) en tanto, no solo subvirtieron el orden social impuesto por el juego de roles sexistas, machistas y patriarcales que las relega a las actividades de la esfera de lo privado (como el cuidado del hogar) y que las ubica en un lugar inferior respecto a los hombres, sino que lograron trascender a la esfera de lo público, constituyéndose como sujetas políticas, críticas y transformadoras, con la capacidad de intervenir e interpelar a sus semejantes y contrapartes en escenario de carácter social, cultural, político y económico.

Para finalizar, es preciso señalar que esta no es la única experiencia existente en Colombia ni en el Abya Ayala, sino que hay diferentes procesos de mujeres desde diversos sectores sociales, que deben ser visibilizadas, reconocidas y fortalecidas a través de la creación de redes de solidaridad, construcción de agendas comunes y concreción de utopías colectivas que 


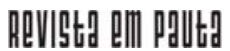

\} MUJERES CAMPESINAS - DIAZ, J. Y. C.; GARCIA, J. Z. \}

DOI: $10.12957 /$ rep.2021.56084

converjan en un bloque histórico contrahegemónico con capacidad nacional, regional y global para abolir este retrógrada sistema capitalista, colonial, patriarcal y heteronormativo. 


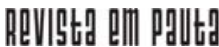

\} MUJERES CAMPESINAS - DIAZ, J. Y. C.; GARCIA, J. Z.

DOI: $10.12957 /$ rep.2021.56084

\section{Referencias}

ASOCIACIÓN DE MUJERES POR INZÁ. Mujeres campesinas de Inzá en junta por la soberanía alimentaria. Revista Semillas, Bogotá, dic. 2019.

CAMPRUBI, B. Comité de mujeres de la Acit: a través de la mujer, todo. Colombia. Disponible en: https://porlatierra.org/casos/173/linea. Acceso en: 6 nov. 2020.

CONTRERAS, P.; TRUJILLO, M. Desde las epistemologías feministas a los feminismos decoloniales: aportes a los estudios sobre migraciones. Barcelona: Athenea Digital, 2017. Disponible en: https://atheneadigital.net/ article/view/v17-n1-trujillo-contreras/1765-pdf-es. Acceso en: 6 nov. 2020.

COORDINACIÓN EUROPEA VÍA CAMPESÍNA. Una guía por la soberanía alimentaria. Bruselas, 2018. Disponible en: https://viacampesina.org/en/ wp-content/uploads/sites/2/2018/02/Food-Sovereignty-a-guide-ES-versionlow-res.pdf. Acceso en: 6 nov. 2020.

DUARTE, C. Análisis de la posesión territorial y situaciones de tensión interétnica e intercultural en el departamento del Cauca. Cali: Pontificia Universidad Javeriana, 2013.

ESPINOSA, Y. De por qué es necesario un feminismo descolonial: diferenciación, dominación co-constitutiva de la modernidad occidental y el fin de la política de identidad. Revista Solar, 2016, año 12, v. 12, n. 1. Disponible en: http://revistasolar.org/wp-content/uploads/2017/07/9-De-porqu $\%$ C3\%A9-es-necesario-un-feminismo-descolonial...Yuderkys-EspinosaMi\%C3\%B1oso.pdf. Acceso en: 6 nov. 2020.

GÓMEZ et al. Estudios decoloniales y poscoloniales. Posturas acerca de la modernidad/colonialidad y el eurocentrismo. Revista Ratio Juris, Medellín, v. 12, n. 24, 2017.

JABARDO, M. Feminismos negros: una antología. Madrid: Traficantes de Sueños, 2012.

KOROL, C. Feminismos populares - Las brujas necesarias en los tiempos de cólera. Buenos Aires: Nuestra Sociedad, 2016. Disponible en: https:// nuso.org/articulo/feminismos-populares/. Acceso en: 6 nov. 2020.

MORALES, A. Du grain à moudre: genre, développement rural et alimentation. Genève: Graduate Institute Publications, 2011.

PORTO-GONÇALVES, C. Abya Ayala. São Paulo: Latinoamericana, 2016. Disponible en: http://latinoamericana.wiki.br/es/entradas/a/abya-yala. Acceso en: 6 nov. 2020.

SOSA, M. ¿Cómo entender el territorio? Guatemala: Universidad Rafael Landiva, 2012. 


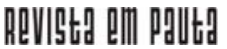

\} MUJERES CAMPESINAS - DIAZ, J. Y. C.; GARCIA, J. Z. \}

DOI: $10.12957 /$ rep.2021.56084

WIGDOR, G.; ARTAZO, G. Pensamiento feminista latinoamericano: reflexiones sobre la colonialidad del saber/poder y la sexualidad. Cultura y representaciones sociales, v. 11, n. 22. México, 2017. Disponible en: http:// www.scielo.org.mx/scielo.php?script=sci_arttext\&pid=S200781102017000100193. Acceso en: 6 nov. 2020.

DOI: $10.12957 /$ rep.2021.56084

Recebido em 09 de março de 2020.

Aprovado para publicação em 18 de abril de 2020.

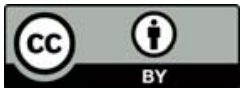

A Revista Em Pauta: Teoria Social e Realidade Contemporânea está licenciada com uma Licença Creative Commons Atribuição 4.0 Internacional. 